\title{
The principles and priorities of Dr T.D. Greenlees, medical superintendent of the Grahamstown Lunatic Asylum, 1890-1907
}

\author{
Rory du Plessis*
}

\section{Introduction}

Eric J Engstrom, a historian of psychiatry, argues that carceral narratives of lunatic asylums have lost their paradigmatic status in the historiography of psychiatry. ${ }^{1}$ One outcome from the movement away from such narratives is that it has "opened up new interest in (and perhaps even greater appreciation of) alienist culture. Picturing asylums as more than just disciplinary institutions enhances our understanding of the varieties and complexities of these strikingly resilient forms of managing madness". 2 A possibility to further enrich our understanding and appreciation of the varieties of asylum culture is available by exploring the significant role played by the medical superintendents of such institutions. For Louise Hide, the superintendent wielded a "considerable amount of influence within the institution and imprinted his personal style of management upon its processes, structures and therapeutic regimes". ${ }^{3}$ Accordingly, by investigating the tenure of a superintendent it is possible to highlight how the individual constructed the asylum to embody a set of goals and principles. ${ }^{4}$ Along these lines, the study aims to explore and investigate the Grahamstown Lunatic Asylum, South Africa, under the medical superintendence of Dr Thomas Duncan Greenlees, from 1890 to 1907.

Thomas Duncan Greenlees (1858-1929) was born in 1858 in Kilmarnock, Scotland. He studied medicine at Edinburgh, graduating with a MB, C.M. in 1882 and an MD in 1901. Prior to taking up the post of the medical superintendent at the Grahamstown Lunatic Asylum, he had significant experience working in British asylums that included being the assistant medical officer at the City of London Asylum at Stone, and later being appointed as the medical officer at the Carlisle Asylum (1884 to 1887) and Dartford Asylum (1887 to 1890). In addition to his post

Rory du Plessis is a lecturer in Visual Culture Studies in the Department of Visual Arts, University of Pretoria (UP). He is pursuing a PhD with the Division of Philosophy and Ethics of Mental Health (UP). The author wishes to acknowledge that the research for this article was supported by a pre-doc fellowship at the Max Planck Institute for the History of Science. Thanks also to the anonymous reviewers for their insightful comments, constructive engagement and generous guidance.

\section{How to cite this article:}

Du Plessis R. The principles and priorities of Dr T.D. Greenlees, medical superintendent of the Grahamstown Lunatic Asylum, 1890-1907. Historia. 2015; 1(1), Art. 24 pages.

http://dx.doi.org/10.17159/2309-8392/2015/v60n1a2

1. E.J. Engstrom, "History of Psychiatry and its Institutions", Current Opinion in Psychiatry, 25, 6, 2012, p 487.

2. $\quad$ Engstrom, "History of Psychiatry and its Institutions", p 488.

3. L. Hide, Gender and Class in English Asylums, 1890-1914 (Palgrave Macmillan, Houndmills, 2014), p 47.

4. N. Tomes, The Art of Asylum-keeping: Thomas Story Kirkbride and the Origins of American Psychiatry (University of Pennsylvania Press, Philadelphia, 1994), p 45. 
at the Grahamstown Lunatic Asylum, he was appointed the surgeon superintendent of the Grahamstown Chronic Sick Hospital and the visiting medical officer to the Institute for the Care and Education of Weak-minded Children.

Greenlees was for several years a member of the Grahamstown and Eastern Province branch of the British Medical Association. His membership at the branch included a number of notable appointments, including serving twice as its president. ${ }^{5}$ Greenlees wrote a substantial number of scientific articles that were published in the leading journals of the time, including the South African Medical Record, ${ }^{6}$ the Journal of Mental Science ${ }^{7}$ and the American Journal of Insanity. ${ }^{8}$ Moreover, he published a number of articles in the newspapers that circulated in Grahamstown and was notably prolific in the talks and speeches that he delivered to the medical community and the general public of the town. On his retirement from the Grahamstown Lunatic Asylum, ${ }^{9}$ he was magnanimously praised for his "whole-hearted enthusiasm and an untiring energy" leadership and administration of the asylum:

He had identified himself with the Institution and its welfare and had done so much for it, that his departure leaves a distinct blank. He is followed into his well-earned leisure by the affectionate regard of his patients and the good wishes of his Staff and of a goodly company of friends in Grahamstown and district, where he was so highly respected. ${ }^{11}$

In order to explore the beliefs, goals and primary topics of Greenlees during his tenure, the asylum's annual reports provide a valuable resource. Although annual reports should not be regarded as an unbiased record of events as they have widely been identified as vehicles to advertise and raise funds for the institute, ${ }^{12}$ they nevertheless remain essential in offering the historian with "insights into the priorities and motivations of the institution, especially those advocated by the superintendents". ${ }^{13}$

From close examination of the annual reports several key topics emerge. (1) Greenlees sought to de-stigmatise the asylum by correcting any misconceptions that the public had regarding insanity and the asylum. This took the form of opening the asylum to visits from the public and sending the patients on excursions to events and activities in Grahamstown and further afield. (2) The social relations and excursions between the asylum's patients and the outside community posed a number of associated risks. For example, patients acting and conducting themselves in ways that could bring into disrepute the de-stigmatised image of the asylum. Thus, Greenlees initiated a number of mechanisms to

5. E.H. Burrows, A History of Medicine in South Africa up to the End of the Nineteenth Century (AA Balkema, Cape Town, 1958), p 343.

6. The journal is now known as the South African Medical Journal.

7. The journal is now known as The British Journal of Psychiatry.

8. The journal is now known as the American Journal of Psychiatry.

9. After his tenure in Grahamstown, Greenlees returned to the United Kingdom to become resident physician and superintendent of the Fenstanton Asylum at Streatham Hill. See Burrows, A History of Medicine in South Africa, p 343.

10. Adler Museum (hereafter AM): A (vol. 7), Reports on asylums for 1907.

11. AM: A (vol. 7), Reports on asylums for 1907.

12. L. Wannell, "Writing the Asylum: Madness, Culture and Subjectivity at the York Retreat, c. 1875-1940", PhD thesis, University of York, 2005.

13. Wannell, "Writing the Asylum", p 55. 
regulate and control the accessibility to the asylum as well as the conduct and behaviour of the visitors and patients. In particular, these mechanisms made special provision for the nurses and attendants to operate on the level of surveillance to ensure that the norms of conduct, relations and discipline were enacted by the visitors to the asylum as well as the resident patients. (3) Greenlees was concerned with encouraging the patronage of private patients to the asylum. In order to attract and secure their patronage, the asylum catered to the luxuries, recreations and amusements that they had been accustomed to. Moreover, the private patients also required a distinct partition between themselves and the rest of the asylum's patients. Accordingly, Greenlees embarked upon an extensive programme of segregation at the asylum. (4) Substantial interest was invested by Greenlees in the training of nurses and attendants as agents in the care and management of the insane. (5) A resounding matter of concern for Greenlees was reducing the total costs of running the asylum.

The identification and investigation of the topics serves to underscore that a diverse range of interests constituted Greenlees's tenure. Nevertheless, these topics are intimately connected to, and indicative of, the tenets of moral therapy. Moral therapy was the main treatment approach and method in the Cape Colony's asylums during the late nineteenth to early twentieth centuries. ${ }^{14} \mathrm{~A}$ core postulation of moral therapy was that the asylum's regimen, setting and therapeutics offered a potential cure to madness. ${ }^{15}$ Along these lines, moral therapy advocated that everyone and everything in the patient's environment influenced their mental condition and therefore possessed therapeutic potential. ${ }^{16}$ Thus the medical superintendents' agents of cure and treatment within the asylum consisted among others of "careful nursing, wholesome diet, regular employments, diversified amusements, cheerful dwelling, personal cleanliness, and such like; these constitute his materia medica, and these he should have at his command at all times". ${ }^{17}$

14. S. Swartz, "The Black Insane in the Cape, 1891-1920", Journal of Southern African Studies, 21, 3, 1995. Moral therapy was first pioneered at the end of the eighteenth century at the Retreat in Yorkshire, England. The therapy offered there can briefly be described as a mild regimen focused on placing patients in a carefully designed environment with the minimal use of physical restraint. Although moral therapy was pioneered at the Retreat, the term itself, along with the first disciplined study of moral therapy, is attributed to the Frenchman Philippe Pinel. In particular, Pinel built on the contribution of the York Retreat to communicate coherently the central principles of moral therapy as a concern with the abolition of all forms of physical punishment and restraint, and to offer patients a regular routine of activities conducted in a restful setting. By the end of the nineteenth century and the early decades of the twentieth century, moral therapy was in the process of being abandoned by the international community. For the most part this was attributed to the waning recovery rates at asylums. Consequently, this led to the overcrowding of asylums that made it nearly impossible to provide the therapeutic activities and tenets of moral therapy. See N.A. Sachs, "Psychiatric Hospitals", in C.C. Marcus and M. Barnes (eds), Healing Gardens: Therapeutic Benefits and Design Recommendations (John Wiley \& Sons, New York, 1999), p 239.

15. J. Parle, States of Mind: Searching for Mental Health in Natal and Zululand, 1868-1918 (University of KwaZulu-Natal Press, Scottsville, 2007), p 50.

16. Sachs, "Psychiatric Hospitals", p 239.

17. W.H.O. Sankey, "Do the Public Asylums of England, as at Present Constructed, Afford the Greatest Facilities for the Care and Treatment of the Insane?", Journal of Mental Science, 2, 1856, pp 466-467. 
In the discussion of the aforementioned topics, the study is informed by current scholarship that posits that the investigation of moral therapy, and its practice at asylums, should be seen as a tension between a desire to promote humane treatment versus a mechanism for inducing conformity and discipline in the patients. ${ }^{18}$ Furthermore, a significant feature of the study is that when discussions of discipline and control do arise, the argument considers a range of Foucault's texts pertaining to notions of power at the asylum. Curiously, very few asylum studies move beyond citing Foucault's History of Madness ${ }^{19}$ at the neglect of including a number of Foucault's later works that present a number of revisions and developments to the text in question. To single out but one source, in Foucault's Psychiatric Power ${ }^{20}$ he critiques a number of notions from the History of Madness that relate to the operations of power at the asylum. ${ }^{21}$ Instead of viewing power as exercised solely by the doctor or medical superintendent, Foucault calls for a new conception of the analysis of power by outlining how it functions through "relays, networks, reciprocal supports, differences of potential, discrepancies, etcetera". ${ }^{22}$ This formation allows for an account of the series of connections and the system of arrangements that surround the medical superintendent - such as the nurses, attendants and supervisors - who in their day-to-day interactions with the patients act as a "kind of optical canal through which the learned gaze, that is to say the objective gaze of the psychiatrist himself, will be exercised". ${ }^{23}$ The superintendent, to this end, is able to supervise all the patients through a relay network of asylum staff who are tasked to constantly provide a close watch of the patients and to relay their observations to him. Consequently, in the asylum:

\begin{abstract}
a system of power [...] is secured by a multiplicity, a dispersion, a system of differences and hierarchies, but even more precisely by what could be called a tactical arrangement in which different individuals occupy a definite place and ensure a number of precise functions. You have therefore a tactical functioning of power or, rather, it is this tactical arrangement that enables power to be exercised. ${ }^{24}$
\end{abstract}

In sum, this study endeavours to explore Greenlees's beliefs and goals during his tenure at the Grahamstown Lunatic Asylum. Specifically, five topics are identified from Greenlees's annual reports. These topics are dealt with in the subsequent sections and examined in the light of recent scholarship on moral therapy and Foucault's analysis of power.

\title{
De-stigmatising the asylum
}

The Grahamstown Lunatic Asylum opened in 1875 with Dr Robert Hullah acting as the first superintendent from 1875 to $1890 .{ }^{25}$ The asylum was built on the site of

18. A. Scull, The Most Solitary of Afflictions. Madness and Society in Britain 1700-1900 (Yale University Press, London, 1993), p 8; S. Rutherford, "The Landscapes of Public Lunatic Asylums in England, 1808-1914", PhD thesis, De Montfort University, 2003, p 84.

19. M. Foucault, History of Madness. Translated by J. Murphy and J. Khalfa (Routledge, London, 2006 [1961]).

20. M. Foucault, Psychiatric Power: Lectures at the College de France, 1973-74. Translated by G. Burchell (Palgrave Macmillan, Houndmills, 2006).

21. A.I. Davidson, "Introduction", in J Lagrange (ed.), Psychiatric Power: Lectures at the College de France, 1973-74 (Palgrave, New York, 2006), pp xiv-xv.

22. Foucault, Psychiatric Power, p 4.

23. Foucault, Psychiatric Power, pp 4-5.

24. Foucault, Psychiatric Power, p 6.

25. This institution was established in 1875 in Grahamstown, a small frontier town populated by British colonial settlers in what is now the Eastern Cape Province of South Africa. For an 
former military barracks. The suitability of the site was not attributed to the existing physical structures but unquestionably to its physical location on an elevated ridge overlooking the Kowie River with 50 acres of well-watered and wooded countryside, suitable for both agriculture and livestock farming. The grounds were extended further and developed in 1883 by planting a boundary hedge. A boundary walk was laid out for the patients' use. Shrubs and annuals were planted within the view from the asylum buildings. ${ }^{26}$ Despite the picturesque setting and therapeutic potential of the site, the asylum operated largely as a custodial institution under Hullah's superintendency. This was in large attributed to the patient population consisting of criminals, paupers and vagrants. ${ }^{27}$

The move to reconfiguring the asylum to offer a curative and humanitarian regime was spearheaded by the appointment of Dr Dodds as the Cape Colony's inspector of asylums from 1889 to $1913 .^{28}$ For Dodds the asylum should no longer be deemed a place of confinement for the insane but as a hospital "to cure the curable and to brighten the lives of those who cannot be cured". ${ }^{29}$ Although Hullah strove to follow Dodds's mandate, there were still significant aspects that were missing. In Dodds's inspection reports he highlighted a number of deficiencies that included the lack of suitable occupations and recreations for the patients. ${ }^{30}$ Following Hullah's death in 1890, Greenlees was appointed as the new medical superintendent.

Greenlees aimed to "make the Asylum more of the nature of a Hospital for the treatment of acute and recoverable cases of insanity". ${ }^{31}$ Crucial in this regard is that Greenlees had to implement a number of changes to the management, care and treatment of patients as well as having to address the public prejudice against asylums and lunatics. ${ }^{32}$ Not only were the public still frightened of asylums, believing them to be closely aligned with "gaols", ${ }^{33}$ but there was a stigma and disgrace attached to "being certified or branded a lunatic". ${ }^{34}$ Even subsequent to a patient's successful recovery and discharge from the asylum, the mere fact that he

in-depth discussion of the history of the Grahamstown Lunatic Asylum, see F. Swanson, "Colonial Madness: The Construction of Gender in the Grahamstown Lunatic Asylum, 1875-1905", BA Honours, University of Cape Town, 1994; F. Swanson, "Of Unsound Mind': A History of Three Eastern Cape Mental Institutions, 1875-1910", MA thesis, University of Cape Town, 2001.

26. Swanson, "Colonial Madness", pp 12-13; 24.

27. Swanson, "Colonial Madness", p 19.

28. William John Dodds (1854-1939), MB, C.M. (1876), MD (1879) a Scottish trained doctor who was appointed inspector of asylums in 1889 and medical superintendent of Valkenberg in 1891. See S. Swartz, "Colonialism and the Production of Psychiatric Knowledge in the Cape, 1891-1920", D.Phil thesis, University of Cape Town, 1996. In Dodds's post as inspector of asylums, he advocated for the humane care of patients in an asylum regimen that included work and recreation in pleasant surroundings. Dodds promoted his beliefs through his regular site inspection of the asylums under his jurisdiction. See Swartz, "The Black Insane in the Cape".

29. AM: A (vol. 5), Reports on asylums for 1891.

30. Swanson, "Colonial Madness"; Swanson, "'Of Unsound Mind"”.

31. AM: A (vol. 5), Reports on asylums for 1890.

32. Wellcome Library (hereafter WL): Pam. vol. (Shelfmark: WM6:1): T.D. Greenlees, "An Address on the Ethics of Insanity", 1910, p 2.

33. T.D. Greenlees, "Medical Social and Legal Aspects of Insanity", South African Medical Record, 1, 8, 1903, pp 121-125.

34. WL: Pam. vol. (Shelfmark: WM6:1): T.D. Greenlees, "Remarks on Lunacy Legislation in the Cape Colony", 1896, p 12. 
or she was once "in an Asylum will injure him socially, and perhaps financially, for the rest of his life". ${ }^{35}$ Owing to such reigning beliefs, the asylum was seen as a place of last resort in the treatment of insanity. ${ }^{36}$ This meant that institutionalisation was avoided by several other options which included seclusion and management of the insane by keeping them at home with the family; nursing homes; and visits to general practitioners. ${ }^{37}$

Greenlees actively sought to "suggest a remedy" for such acts of public prejudice. ${ }^{38}$ One such means was by opening the asylum to visits from the public. ${ }^{39}$ Greenlees boldly posited that such events helped to mitigate the stigma against asylums: "the more the public know of the internal working of an asylum the sooner will their prejudice against such institutions disappear". ${ }^{\circ}$

The opening of asylums to the general public provided an opportunity to showcase the asylum and its humanitarian efforts in the treatment of the insane. ${ }^{41}$ In this regard, asylum visiting held the potential to initiate public confidence in the asylum, while potentially acting to de-stigmatise public perceptions of lunacy and asylums. ${ }^{42}$ Opening the asylum to visitors also provided a valuable link between the asylum and the community to establish a sense of acceptance. Members of the community were able to contribute to the well-being, comfort and happiness of patients by offering a number of services to the patients like offering entertainment and a range of recreational activities. Examples recorded in the annual reports were concerts, dramatic entertainments and magic lantern shows. Not only was public visiting an opportunity to gain the public's confidence by acquainting them with the asylum and its workings but it also enlisted their "active philanthropy" vision to support the care of the insane. ${ }^{43}$

Apart from visitors to the asylum, another effective means of destigmatising the asylum and insanity was taking the patients out on excursions to events and activities in Grahamstown and further afield. ${ }^{44}$ To elucidate further, the excursions also acted to correct any prevailing misconceptions that the public had

35. Greenlees, "Medical Social and Legal Aspects of Insanity", p 122.

36. Greenlees, "Medical Social and Legal Aspects of Insanity", p 122; T.D. Greenlees, "Statistics of Insanity in Grahamstown Asylum", South African Medical Record, 3, 11, 1905, p 222.

37. J. Parle, States of Mind, p 168. For Parle such findings reveal that the asylum is far removed from being the "dominant institutional or even discursive space" for the care and treatment of insanity during colonialism. See Parle, States of Mind, p 7.

38. Greenlees, "An Address on the Ethics of Insanity", p 2.

39. Western Cape Archives and Records Service (hereafter WCARS): CCP 1/2/1/108, Reports on asylums for 1898 .

40. WCARS: CCP $1 / 2 / 1 / 104$, Reports on asylums for 1897 . The opening of the asylum to visitors in order to give "the community an opportunity of being disabused of old prejudices" and of knowing the kind of therapy offered at the asylum was advocated by prominent figures in asylum management. See T.S. Kirkbride, On the Construction, Organization and General Arrangements of Hospitals for the Insane, with some Remarks on Insanity and its Treatment (Pennsylvania Hospital for the Insane, Philadelphia, 1854), p 68. See also C. Mercier, Sanity and Insanity (Walter Scott, London, 1890).

41. WCARS: CCP 1/2/1/108, Reports on asylums for 1898.

42. R. du Plessis, "Popularising and Promoting the Asylum: Photography and Image making at the Grahamstown Lunatic Asylum, 1890-1907", Image and Text, 22, 2013, pp 99-132.

43. Greenlees, "Remarks on Lunacy Legislation in Cape Colony", p 1.

44. AM: A (vol. 5), Reports on asylums for 1891 and 1893. 
regarding insanity and the image of the asylum. ${ }^{45}$ For Mercier (1851-1919), a prominent psychiatrist of the nineteenth century, the usual conception that the public had regarding lunatics was of individuals "raving, shouting at the top of [their] voices, and smashing the furniture". ${ }^{46}$ Patient excursions undermined such stereotypical perceptions by presenting to the public how "wonderfully little difference there is between [the insane] and other people". ${ }^{47}$

The asylum's annual reports made continual reference to the excursions offered to the patients. ${ }^{48}$ Notably the excursions included visits to the town to see the circus, the cinematograph, marionettes, to hear the phonograph and to picnic at places of interest in the neighbourhood. ${ }^{49}$ Moreover, for several years Greenlees was able to secure a sea-side house in Port Alfred for the use of convalescent patients who were sent there for weeklong visits. ${ }^{50}$ The visits to the sea and to the activities on offer in Grahamstown were believed to prove advantageous as they provided an invigorating change of surroundings that could help in dissipating feelings of monotony within asylum life. ${ }^{51}$

In sum, Greenlees instituted a number of effective means to offer both patients and visitors with opportunities to engage with one another and to enter the space of either the asylum or outside world. ${ }^{52}$ For Greenlees a primary objective for developing such a porous or permeable nature of the asylum with the outside community was to de-stigmatise the asylum and insanity. ${ }^{53}$ Yet it must be underscored that the asylum's permeability did not consist of free and unrestricted movement but rather involved a number of mechanisms to regulate and control the accessibility to the asylum as well as the conduct and behaviour of the visitors. In this way, the asylum should not be seen as a site offering the visitors unimpeded accessibility but rather as constituted by a "controlled openness" 54 that operated via rules and guidelines to govern access to the asylum as well as regulate the conduct and relations of visitors. ${ }^{55}$

45. Mercier, Sanity and Insanity, p xiii.

46. Mercier, Sanity and Insanity, $\mathrm{p} x \mathrm{xv}$.

47. Mercier, Sanity and Insanity, $\mathrm{p}$ xvi.

48. AM: A (vol. 5), Reports on asylums for 1891 and 1893.

49. WCARS: CCP 1/2/1/108, Reports on asylums for 1898.

50. AM: A (vol. 5), Reports on asylums for 1893.

51. AM: A (vol. 5), Reports on asylums for 1891, 1892, 1893.

52. While the emphasis has been placed on Greenlees's efforts to de-stigmatise the asylum by opening it up to visitors from the public, a significant number of the visitors consisted of friends and family of the patient. A visit by a relative or acquaintance was seen to comfort and alleviate the suffering of the patients. See C. Mercier, Lunatic Asylums: Their Organisation and Management (Charles Griffin \& Co., London, 1894), p 240. On a cursory inspection, it appears as if Greenlees used the casebooks to record the visitors that each patient received. Of significance though is that Greenlees used these visits to observe the patient's behaviour and interactions. The patient's ability to engage and maintain interpersonal contact with the visitor was deemed to be an indicator of improvement.

53. C. Coleborne, "Challenging Institutional Hegemony: Family Visitors to Hospitals for the Insane in Australia and New Zealand, 1880s-1910s", in G. Mooney and J. Reinarz (eds), Permeable Walls: Historical Perspectives on Hospital and Asylum Visiting (Rodopi, Amsterdam, 2009), p 290; D. MacKinnon, "Divine Service, Music, Sport, and Recreation as Medicinal in Australian Asylums 1860s-1945", Health and History, 11, 1, 2009, p 267.

54. A. Digby, "Moral Treatment at the Retreat, 1796-1846", in W.F. Bynum, R. Porter and M. Shepherd (eds), The Anatomy of Madness: Essays in the History of Psychiatry, Volume 2 (Tavistock, London, 1985), p 55.

55. M. Foucault, "Of Other Spaces", Translated by J. Miskowiec, Diacritics, 16, 1, 1986, p 26. 


\section{A system of surveillance}

The social relations and excursions of the asylum with the outside community and surrounding environs had a number of associated risks. Unsolicited visitors to the asylum were problematic as were patient escapes and patients acting and conducting themselves in ways that could counter the de-stigmatised image of the asylum that Greenlees sought to represent to the public. These potential risks were kept in check by the Government Notice (No. 262 of 1893) titled the "Regulations for the management of asylum" ${ }^{56}$ as well as Greenlees's published documents pertaining to the instruction of nurses and attendants. ${ }^{57}$ Collectively all of these documents made special provision for the nurses and attendants to operate on the level of surveillance to ensure that the norms of conduct, relations and discipline were enacted by the visitors to the asylum as well as the resident patients.

A visit to the asylum required that the individual had to abide by the visiting regulations. The rigid enforcement of these regulations was the responsibility of the nurses and attendants of the asylum. These employees were mandated to ensure that the relatives of patients were only allowed to visit on the days of the week and at the hours directed by the superintendent. Moreover, visitors without a friend or family member at the asylum were only allowed to enter with permission from the superintendent. Their visit was subject to being accompanied by the superintendent or someone appointed by him for such a purpose. ${ }^{58}$ By implementing this system, it is clear that Greenlees was able to police the public's access to the asylum. Beyond mediating the views of the asylum, such visiting policies may have also protected patients from visitors who came out of voyeuristic intrigue. Greenlees abhorred the "curiosity some of the public show to see the interior of an asylum, and its inmates" and took every opportunity of discouraging such visits. ${ }^{59}$ While Greenlees encouraged the visits of the well-intentioned individual who - whether out of humanitarian duty, compassion or charity contributed to the wellbeing of the patient, ${ }^{60}$ he opposed any visitors with dastardly motives. Thus, through a system of rules, Greenlees was able to refuse access to possible undesirable persons who might perform unscrupulous acts on the pretence of visiting a patient. His decisive action ensured that the conduct of visitors who were granted admittance to the asylum remained aboveboard.

A fascinating feature of the visiting regulations is that it placed outsiders under the surveillance of nurses and attendants of the asylum. In terms of Foucauldian studies, this is a new avenue for research that sets out to examine

\footnotetext{
56. WCARS: CO 7170, Regulations for the management of asylums. Government Notice number 262 of 1893.

57. WCARS: CO 1522, Special Instructions to the Nursing Staff having charge of suicidal patients. Printed at Fort England, Grahamstown, 1892; T.D. Greenlees, The Nursing and Management of the Insane (Asylum Press, Grahamstown Asylum, 1892).

58. WCARS: CO 7170, Regulations for the management of asylums.

59. WL: Pam. vol. (Shelfmark: WM6:1): T.D. Greenlees, "The Brain: Its Development, Architecture, Functions and Education", 1892, p 25.

60. It is also reasonable to suggest that the visitors to the asylum could have consisted of individuals who were considering asylum treatment for an insane relative or friend. See Tomes, The Art of Asylum-keeping, p 132.
} 
how visitors were also subject to the asylum's operations of power. ${ }^{61}$ The asylum staff was directed to monitor the behaviour and conduct of visitors and report to the superintendent anything improper that they might notice. Particularly, the visitors were monitored in their relations and conduct to the patients. If their visit was in anyway detrimental or inexpedient to the wellbeing of the patient, they would not be granted permission to visit again. Although visitors were able to hold a private conversation with the patient, this was limited only to same-sex interactions. The possibility of private conversations between a male and female were only permitted in the presence of an attendant or a third person who was not a patient. ${ }^{62}$ In so doing, the visitors were allowed a degree of privacy with the patient but without the threat being posed of any scandalous sexual couplings taking place at the asylum. In these instances, it becomes evident that there was a certain degree of behavioural conditioning in the visitors in order for them to gain re-admittance to the asylum and to preserve their links with their friends or family members. $^{63}$

The nurses and attendants were required to have a constant supervision of the patients. ${ }^{64}$ "Not to be out of sight and to be continually under supervision", ${ }^{65}$ was the way asylum employees were instructed to oversee the patients. Whether the patients were in the ward, at work, being entertained by amusements or simply outdoors they were always to be kept in view. It was precisely the staff's vigilance that was provided by Greenlees as one of the factors that led to the diminishing number of escapes at the asylum. ${ }^{66}$

Apart from surveillance, another Foucauldian interpretation to account for the low number of escapes is that it was only trustworthy patients who received the privilege of a large amount of liberty and opportunities for personal parole. ${ }^{67}$ Even by 1904 when the airing court was opened to the outside environment, only one patient escaped from it out of a larger group of 15 to 20 patients who spent most of their time occupying the space. ${ }^{68}$ That the patients rarely escaped from the airing court or from personal parole, is indicative of an encompassing disciplinary system in which patients were confined to "a system of rewards and

61. G. Mooney and J. Reinarz, "Hospital and Asylum Visiting in Historical Perspective: Themes and Issues", in G. Mooney and J. Reinarz (eds), Permeable Walls: Historical Perspectives on Hospital and Asylum Visiting (Rodopi, Amsterdam, 2009), p 23.

62. WCARS: CO 7170, Regulations for the management of asylums.

63. See Mooney and Reinarz, "Hospital and Asylum Visiting in Historical Perspective", p 23.

64. WCARS: CO 7170, Regulations for the management of asylums.

65. WCARS: CO 1522, Special instructions to the nursing staff having charge of suicidal patients.

66. WCARS: CCP 1/2/1/97, Reports on asylums for 1895; WCARS: CCP 1/2/1/101, Reports on asylums for 1896. In 1894 a large number of 16 escapes occurred. By 1895 the number of escapes dropped to 6 owing to the increased vigilance on the part of the nursing staff. In most instances the escapees were returned to the asylum within a short period of time. Every case of escape was communicated without delay to the police followed by a search party of asylum staff on horse-back. The prompt course of action, concerted efforts and manoeuvres to return the patients to the asylum can be ascribed to the community's concerns regarding suicidal and dangerous escapes from the asylum. See WCARS: CCP $1 / 2 / 1 / 97$, Reports on asylums for 1895. For a discussion of a local community's opposition to an asylum owing to patient escapes, see R. Ellis, "A Constant Irritation to the townspeople"? Local, Regional and National Politics and London's County Asylums at Epsom", Social History of Medicine, 26, 4, 2013, pp 653-671.

67. WCARS: CCP 1/2/1/101, Reports on asylums for 1896.

68. AM: A (vol. 6), Reports on asylums for 1904. 
punishments". ${ }^{69}$ In other words, the asylum functioned according to a system that encouraged patients to co-operate in becoming docile, to manage their own behaviour in order to assure their lack of restrictions and guarantee their rewards. Thus, for the patients to retain access to certain spaces, such as frequenting the airing court, and to receive certain privileges like being granted parole, they had to exercise self-control and good behaviour. If they misbehaved or abused their privileges they would have had them revoked. A further expression of this disciplinary system is evident in the amusements and entertainments offered to the patients. During such activities, Greenlees remarked that the patients' conduct is "everything that could be desired". ${ }^{70}$ This statement is a clear example of the pervasive penetration of a disciplinary system that instils in the patients selfrestraint and good behaviour in order for them to continue to receive entertainment privileges.

The exchanges between the patients and the wider public during performances and excursions were also mediated by a disciplinary system that guaranteed the patients' best behaviour. This is exceptionally apparent in the extensive guidelines given to staff on maintaining the order and conduct of patients when moving beyond the perimeter of the asylum:

\begin{abstract}
When exercising in the open country beyond the asylum grounds, the patients shall be induced to walk in a quiet and orderly manner, and shall be prevented from speaking to or molesting any one on the road, from leaving the ranks or straggling in any way, and from entering a house or shop upon any pretext whatever. It is to be remembered that the opportunity of walking in the open country is a great privilege which will have to be withdrawn on the occurrence of any irregularity or misconduct. It is hoped that this fact will be continually borne in mind by the attendants, and impressed by them upon the patients, so that their co-operation may be secured in maintaining order and suppressing any disturbance or irregularity, which might lead to a deprivation that would be keenly felt by many of the inmates. ${ }^{71}$
\end{abstract}

The excursions by the patients and the visits to the asylum by members of the public never provided a direct observation of the asylum and its patients. Instead, they included only the patients who earned the privilege to do so and who maintained propriety throughout the course of the event. Through the deployment of a disciplinary system, the behaviour of the patients was not necessarily an expression of their individual temperament or personality but rather more closely resembling a choreographed performance of normality, civility, good manners and respectability. Within the encompassing world of surveillance and discipline, Greenlees was able to manufacture and manage a meticulous de-stigmatised image of the asylum.

\title{
Encouraging patronage from private patients
}

Although the preceding discussions have indicated that the de-stigmatised image of the asylum should not be regarded as an accurate and unadulterated view of the institution, it nevertheless offered Greenlees the means to overturn the previously negative image of the asylum. It is reasonable to suggest that

69. M. Foucault, Madness and Civilization: A History of Insanity in the Age of Reason. Translated by R. Howard (Routledge, London, 2009 [1967]), p 237.

70. WCARS: CCP 1/2/1/101, Reports on asylums for 1896.

71. WCARS: CO 7170, Regulations for the management of asylums. 
Greenlees's efforts at de-stigmatising the asylum provided a decisive role in contributing to "the increased confidence" that the public had regarding the institution. ${ }^{72}$ Even the South African Medical Journal reported in 1897 that "people do not hesitate now as they formerly did to send a friend for treatment to the Asylum". ${ }^{73}$ Yet Greenlees was not very enthusiastic by the upsurge of cases that were sent to the asylum. For the most part they were non-paying patients from the lower classes. ${ }^{74}$ Instead, Greenlees's interest lay in attracting private patients "of a better class at an early stage of insanity". ${ }^{75}$ But it was precisely this class of patients who were reluctant to resort to asylum treatment and instead preferred a range of alternative options. ${ }^{76}$ One specific treatment option was admittance to a sanatorium. ${ }^{77}$ The sanatoriums provided a suitable means to bypass the social stigma attached to asylums while offering hospital care that operated on the level of a "luxury hotel". ${ }^{78}$ From the 1890 s a number of sanatoriums were advertised in The Grahamstown Journal. These included, amongst others, the Claremont Medical and Surgical Sanitarium; Stone's Hill Sanitarium; Zuurberg Hotel and Sanatorium; and the Howieson's Poort Sanatorium. ${ }^{79}$

One of the reasons why private patients sought treatment in a sanatorium was because of the fear of being denied the access or the opportunity to engage in their accustomed luxuries, recreation and amusements. Accordingly, to attract and secure the patronage of private patients to an asylum, the institute's accommodation typically incorporated the character, appearance and facilities of a gentleman's residence and way of life. ${ }^{80}$ Within this environment the patients were able to emulate the middle and upper classes' pattern of life. In doing so, these patients retained their social class standing and individuality from prior living circumstances to institutionalisation. At the Grahamstown Lunatic Asylum, the private patients were well catered for because Greenlees paid scrupulous attention to their needs. The private patients were offered twice daily drives into the surrounding countryside by horse and carriage and were often sent to the seaside in Port Alfred for the day. ${ }^{81}$ This was over and above the respective gentlemanly and ladylike indoor recreations as well as the ornately decorated wards and luxurious furnishings. ${ }^{82}$

72. AM: A (vol. 6), Reports on asylums for 1904.

73. Cited in Swanson, "Colonial Madness", pp 38-39.

74. AM: A (vol. 6), Reports on asylums for 1904.

75. AM: A (vol. 5), Reports on asylums for 1890.

76. A. Scull, "The Insanity of Place", History of Psychiatry, 15, 4, 2004, p 426.

77. H. Deacon, E. van Heyningen, S. Swartz and S. Swanson, "Mineral Wealth and Medical Opportunity", in H. Deacon, H. Philips and E. van Heyningen (eds), The Cape Doctor in the Nineteenth Century: A Social History (Rodopi, Amsterdam, 2004), p 235; Parle, States of Mind, p 168.

78. Deacon, van Heyningen, Swartz and Swanson, "Mineral Wealth and Medical Opportunity", p 235.

79. It remains unclear whether the abovementioned sanatoriums operated as medical facilities or merely luxurious retreats. Yet, there is evidence that the Claremont Medical and Surgical Sanitarium received patients suffering from mania, melancholia and other forms of mental illness. See WCARS: CO 8052, Claremont medical and surgical sanitarium, 1899.

80. W.L.I. Parry-Jones, The Trade in Lunacy: A Study of Private Madhouses in England in the Eighteenth and Nineteenth centuries (Routledge, London, 1972), p 105.

81. AM: A (vol. 5), Reports on asylums for 1892; AM: A (vol. 6), Reports on asylums for 1903.

82. The asylum's close proximity to the middle and upper class mode of life was a feature and provision reserved for private patients. For the majority of the patients who were supported by the government, a "most rigid economy" ensured that their comfort was maintained but that they were excluded from the luxury provisions of the private patients. See T.D. 
In 1899 a new block for male private patients was opened and provided eight bedrooms "for gentleman paying the highest rates of board". 83 The accommodation of the new block was praised by Greenlees as being "excellent" ${ }^{84}$ and contributed to an increase in the number of receipts from private patients. ${ }^{85}$ Yet, the ward was not exactly what Greenlees had originally envisaged for private patients. Over several annual reports, Greenlees had recommended the remodelling of an existing building known as the Residency for private patients. ${ }^{86}$ The reason for the choice of the building was that it was quite a distance away from the asylum and thus "none of the objections created by being an inmate of the asylum would apply to patients residing there". ${ }^{87}$ When this proposal was not favoured by the government, Greenlees proposed the erection of several villas on the asylum estate. ${ }^{88}$ In this way, Greenlees's proposals can be read as an attempt to construct a separate space in the asylum reserved for private patients. Accordingly, Greenlees was not only concerned with the accommodation and facilities for private patients but also in ensuring that they had their own distinctly designated space that remained separate from the rest of the asylum's patients.

Asylum superintendents identified that private patients feared the indiscriminate intermingling of patients from lower socio-economic classes as well as chronic patients. Specifically, the private patients believed that it would be injurious to their social standing to associate with those of a lower class. Thus private patients required asylum facilities that maintained a separation of classes. ${ }^{89}$ In the Cape Colony however, it was not only the separation of class that was required but the partitioning of race as well. To elucidate further, Greenlees argued that:

\begin{abstract}
there is a strong feeling in this part of the Colony that European and native cases of insanity should not be treated in the same building; or if complete separation is not feasible, that arrangements should be made to house them in buildings quite apart from those occupied by Europeans. There is much to be said in favour of this plan: when it is considered that no asylum in the Colony can boast of such a large income from private patients as this institution - some of these cases paying as much as $£ 3$ 3s. per week - surely some consideration should be given to the natural prejudices of their friends, that their afflicted relatives should not be allowed to associate with the native. ${ }^{90}$
\end{abstract}

However, it was only in 1904 with the opening of Douglass House that Greenlees was able to offer private patients - albeit just for females - a specially

Greenlees, Insanity: Past, Present, and Future, Presidential address delivered to The Grahamstown and Eastern Province Branch of the British Medical Association (Asylum Press, Grahamstown, 1903), p 19.

83. WCARS: CCP 1/2/1/112, Reports on asylums for 1899.

84. WCARS: CCP 1/2/1/115, Reports on asylums for 1900.

85. WCARS: CCP 1/2/1/118, Reports on asylums for 1901.

86. WCARS: CCP 1/2/1/97, Reports on asylums for 1895; WCARS: CCP 1/2/1/101, Reports on asylums for 1896 .

87. WCARS: CCP 1/2/1/97, Reports on asylums for 1895.

88. WCARS: CCP 1/2/1/104, Reports on asylums for 1897.

89. Scull, MacKenzie and Hervey, Masters of Bedlam: The Transformation of the MadDoctoring Trade, pp 107-108.

90. AM: A (vol. 5), Reports on asylums for 1893. 
designated villa residence that was separate from the other wards of the asylum. ${ }^{91}$ The private male patients never received the equivalent of Douglass House and remained in the accommodation provided by the purpose-built ward of 1899 . Additionally, prior to the opening of Douglass House, the female private patients were still accommodated in the general female wards. Thus there was considerable effort on Greenlees's part to ensure that the asylum could ascribe to the private patients' wishes to be excluded from the rest of the asylum populace. Greenlees's efforts in this regard take three inter-related forms. ${ }^{92}$ First, private patients were kept separate from the asylum population by physical structures such as partitions that established spaces reserved for the use of specific patient groups that were classified according to their sex, race, class and form of insanity. This segregation of the asylum was sustained via the means of surveillance that effectively safeguarded "a cocoon of luxury, tranquillity and restoration for white private patients". ${ }^{93}$

Second, Greenlees embarked on an intensive programme of transferring patients who were chronic, criminally insane and non-paying, to several other asylums to purposively give rise to a patient profile that befitted his intention for the asylum: as a place for acute and recent cases of insanity. ${ }^{94}$ By instituting a large number of transfers, Greenlees created a "rapid circulation"95 of the patient population from the Grahamstown Lunatic Asylum to other facilities. From as early as 1890, Greenlees transferred "quiet demented patients" to Port Alfred Asylum to make room for acute cases requiring treatment. ${ }^{96} \mathrm{~A}$ prominent priority for Greenlees was the transfer of the criminally insane from the asylum to Robben Island. ${ }^{97}$ Greenlees was vociferous in his disdain for the admission of such patients and chided the government to take into account that:

It would be well if, in future, cases of this nature were admitted directly to Robben Island, for their admission and detention here is neither safe, nor is it conducive to

91. The accommodation of Douglass House consisted of "three sitting rooms, with matron's quarters, downstairs, and three dormitories, with 7 small bedrooms, upstairs, with ample bath and lavatory requirements. There is one suite of rooms, with a pretty outlook, for a lady with her nurse, who is prepared to pay a higher rate of board. Altogether excellent accommodation is provided for 30 patients, exclusive of a nursing staff, consisting of matron and 5 nurses. The grounds are ample, and will be laid out as gardens, and there are no walls, or anything to give one the impression that this is an Asylum". See: AM: A (vol. 6), Reports on asylums for 1904.

92. For a discussion of the spatial arrangements and segregation at Valkenberg, see J. Louw and S. Swartz, "An English Asylum in Africa: Space and Order in Valkenberg Asylum", History of Psychology, 4, 1, 2001, pp 3-23.

93. R. du Plessis, "The Influence of Moral Therapy on the Landscape Design of Lunatic Asylums Built in the Nineteenth Century", De arte, 86, 2012, p 33.

94. Swanson, "'Of Unsound Mind"”, p 3.

95. WCARS: CCP 1/2/1/104, Reports on asylums for 1897.

96. AM: A (vol. 5), Reports on asylums for 1890. Port Alfred Asylum (1889) and Fort Beaufort Asylum (1894) were established as institutions exclusively for long term patients. Port Alfred was reserved for chronic and elderly patients of all races, while Fort Beaufort was established to care exclusively for black men. In 1897 a separate division for black women was opened at Fort Beaufort. See Swanson, "'Of Unsound Mind”, p 3.

97. AM: A (vol. 5), Reports on asylums for 1892. For further discussion on the Robben Island Lunatic Asylum (1845), see H.J. Deacon, "Madness, Race and Moral Treatment: Robben Island Lunatic Asylum, Cape Colony, 1846-1890", History of Psychiatry, 7, 26, 1996, pp 287-297; H. Deacon, "Racial Categories and Psychiatry in Africa: The Asylum on Robben Island in the Nineteenth Century", in W. Ernst, and B. Harris (eds), Race, Science and Medicine, 1700-1960 (Routledge, London, 1999), pp 101-122. 
the idea that this institution is being reserved for the treatment of acute cases of insanity, uncomplicated by crime. ${ }^{98}$

By the various transfers of patients, Greenlees ensured that there was, for the most part, always availability for paying patients. Yet, it is also reasonable to suggest that the transfers eliminated a number of patients who may have been unfavourably looked upon by the private patients. In this way, the transfers could be regarded as a tacit assurance on Greenlees's part to care and cater for the interests of the private patients.

Third, the private patients were segregated from the rest of the asylum by a treatment regimen that largely pertained to recreation and amusement. A kernel of moral therapy was that asylums, in their effort to treat patients, were required to offer patients an extensive daily programme of remedial occupation and recreation and/or amusement. Yet, at the Grahamstown Lunatic Asylum, the provision and extent of the offerings varied according to the race and class of the patient. White patients were offered a range of voluntary remedial occupation which, for men, included gardening, while women were engaged in indoor activities such as sewing and knitting. ${ }^{99}$ These occupations were punctuated by regular recreational activities and engagements - from sport, indoor games, plays, dances, to excursions. In contrast, black patients were chiefly employed in heavy-duty labour such as farming for men, while the women supplied domestic labour for the wards and kitchens. Black patients were given very few options but to work. The precedent was always that work was prioritised over and above the participation in recreational pursuits. ${ }^{100}$ When amusements were offered, they were primarily in the form of events reserved for black patients. For instance, while white patients were offered weekly dances, blacks were restricted to one dance a month. ${ }^{101}$

Apart from race, the treatment regimen offered at the asylum was manifestly marked by the class of the patient. The private patients appear to have received no remedial occupation, they were never exposed to any outdoor drudgery or the toils of ward work but behaved like leisured individuals engaging and immersing themselves in entertainments, tea parties, carriage drives and excursions. Although the government saw the provision of carriage drives twice daily for private patients as extravagant, Greenlees begged to differ, and saw them as a necessary and routine treatment option for such a class of patients. ${ }^{102}$ The carriage drives and other luxuries were for the exclusive use of the private patients. Thus in the participation of these activities, the private patients found themselves effectively leading a lifestyle that exuded privilege, wealth and status.

Although Greenlees faced numerous difficulties in maintaining the separation of private patients from the rest of the asylum's population, the degree to which Greenlees was successful in this endeavour may be indicated by the growing increase in the income from such patients. Triumphantly Greenlees

98. AM: A (vol. 5), Reports on asylums for 1892.

99. For a specific discussion of the gendering of such activities at Valkenberg, see S. Swartz, "Lost Lives: Gender, History and Mental Illness in the Cape, 1891-1910", Feminism and Psychology, 9, 2, 1999, pp 152-158.

100. Swanson, "Colonial Madness", p 24; Swanson, “'Of Unsound Mind”, p 134; Swartz, "Lost Lives", p 154.

101. WCARS: CCP 1/2/1/101, Reports on asylums for 1896.

102. AM: A (vol. 6), Reports on asylums for 1905. 
proclaimed that the rise in receipts from private patients "provided continued proof that we retain the confidence of the public of a better class". ${ }^{103}$ In sum, Greenlees effectively created an asylum that was split and segregated into categories of race and class. ${ }^{104}$ Each specific category of patients was governed by a distinctive ethos and regimen within a partitioned space of the asylum. For white private patients the asylum operated like a sanatorium by offering a milieu that was luxurious, leisurely and based on social class values. In contrast, black patients were largely regarded as an unpaid labour force within the asylum, and accordingly, the asylum operated more along the lines of a workhouse for them. ${ }^{105}$

\section{Nurses and attendants: agents of care and surveillance}

Greenlees noted that prior to his appointment, ${ }^{106}$ the Cape Colony did not offer any training to the nurses and attendants of an asylum and that it had appeared to him that they were "simply pitchforked into their respective wards without any previous knowledge of their duties". ${ }^{107}$ Aiming to correct this negative state of affairs, Greenlees established a number of lectures and courses in the care and management of the insane for nurses and attendants. ${ }^{108}$ For Greenlees, "trained nurses are as essential in the wards of an asylum as they are in the wards of a general hospital". ${ }^{109}$ As such, the course of lectures on the care and management of the insane aimed to equip the nurses and attendants with the principles and practices of caring for the insane. This included information on mental and nervous diseases and their treatment - from massage, baths and hypnotism. ${ }^{110}$ The

103. AM: A (vol. 6), Reports on asylums for 1903.

104. An in-depth investigation of the asylum population by race and class will require the tabulation of the data for each year from 1890-1907. Such a quantitative investigation is outside the scope of the study.

105. Swanson, "Colonial Madness", pp 25-26; Swartz, "The Black Insane"; Swartz, "Lost Lives", p 154.

106. T.D. Greenlees, "Lunacy Administration in the Cape Colony", British Journal of Psychiatry, 56, 1910, p 270.

107. One possible reason for the apparent haphazard and indiscriminate assignment of duties was that there was difficulty in getting the vacancies for nurses and attendants filled. The situation was so dire that nurses were often imported from the UK. See Greenlees, Lunacy Administration in the Cape Colony", p 271; and Swanson, "Colonial Madness". The recruitment of nurses from the UK was also posed as a solution to staff shortages in Australian asylums in the nineteenth-cenury. See L-A. Monk, "Working in the Asylum: Attendants to the Insane", Health and Society, 11, 1, 2009, p 87.

108. Once Greenlees became associated with the Medico-Psychological Association in its training and examinations, he was able to offer the nursing staff certificates from the Association after they passed an examination. The other asylums of the Cape Colony soon followed Greenlees's lead and presented a number of their nurses for examination. See Greenlees, "Lunacy Administration in the Cape Colony", p 271. Although Greenlees was able to a degree to uplift the status of asylum nursing, his tenure was still characterised by a high level of vacancies and staff turnovers. This was most evident with regard to the male attendants that left the employ of the asylum to follow the gold rush in Johannesburg or to join the South African War. Apart from the names of the attendants and nurses who obtained the nursing certificate at the asylum (For example, see AM: A (vol. 6), Reports on asylums for 1903), the annual reports do not provide any demographic information or details of the staff. I have been unable to establish if the demographical data is available in any other archived source material.

109. AM: A (vol. 5), Reports on asylums for 1892.

110. T.D. Greenlees, The Nursing of Nervous and Mental Diseases: A Lecture Delivered to the Senior Nurses, Albany General Hospital, Grahamstown (The Asylum Press, Grahamstown, 1896) 
lectures also aimed to "educate the staff up to a proper standard of excellence", ${ }^{111}$ which entailed instructing and training them to the levels of service, conduct and personal qualities required by Greenlees at the asylum. These meticulous standards were buttressed and enforced by the "Regulations for the Management of Asylums" (Government Notice, No. 267, 1892) and the 1897 Lunacy Act.

The following discussion aims to explore how the lectures and regulations cast the nurses and attendants as central to offering moral therapy at the asylum; patient observation; and the monitoring of the patients' wellbeing. A second aim is to provide a Foucauldian reading of the regulations in order to investigate how they established a "hierarchical channel culminating in the head doctor, the single person in charge of the asylum". ${ }^{112}$ This hierarchical organisational plan ensured that the nurses and attendants "reinforced rather than countermanded the superintendent's authority". ${ }^{113}$ Furthermore, in order to guarantee the performance of their work duties and the maintenance of high standards, they were under Greenlees's surveillance. Thus, it will be argued that the surveillance of the patients by the nurses and attendants was equally matched by Greenlees's supervision of the staff.

In moral therapy, a principle means of treatment was to divert the patient from any morbid and melancholic thoughts and to rouse in them instead "a new and healthy direction"114 through amusements and forms of recreation. It was the duty of the nurses and attendants to do "their utmost to occupy, amuse, and interest every patient". ${ }^{115}$ This mandate included not only the attendance of the staff at entertainment events but to even present such offerings. In the annual reports, the staff was thanked on numerous occasions for providing concerts and dramatic entertainment for the amusement of the patients. ${ }^{116}$ For those members of staff who were unable to offer musical or other entertainment, participation with the patients in the amusement event was required: "At the dances it shall be their duty to dance with such patients of the opposite sex as are inclined to join". ${ }^{117}$

The rules and regulations for attendants, servants and others ${ }^{118}$ not only indicated the aforementioned duties of the nurses and attendants but also "imposed exacting standards" 119 on the distinctive personal qualities and traits required from the asylum staff: "Kindness and tact, firmness and good temper, thoughtful attention to duty, cheerful obedience to orders, a kind interest in each

111. AM: A (vol. 5), Reports on asylums for 1890.

112. Foucault, Psychiatric Power, p 103.

113. A. Scull, Madhouses, Mad-doctors, and Madmen: The Social History of Psychiatry in the Victorian Era (University of Pennsylvania Press, Philadelphia, 1981), p 137.

114. WCARS: CO 7170, Regulations for the management of asylums.

115. WCARS: CO 7170, Regulations for the management of asylums.

116. WCARS: CCP $1 / 2 / 1 / 108$, Reports on asylums for 1898 . The provision of recreation by staff was such a key therapeutic pivot that even Greenlees was a member of the asylum band known as "The Fort England Nightingales". Moreover, in the advertisements for attendant posts special mention was always made to the extra income offered to individuals who could provide musical services. See "Grahamstown Asylum", The Grahamstown Journal, 08/01/1901.

117. WCARS: CO 7170, Regulations for the management of asylums.

118. WCARS: CO 7170, Regulations for the management of asylums.

119. Digby, "Moral treatment at the Retreat", p 58. 
patient, and orderly neatness in ward duties, should be characteristics of every attendant". ${ }^{120}$

The startling focus on the personal qualities of the staff can be accounted for in a number of ways. As previously outlined, paramount importance was placed on offering entertainment and recreation to the patients. In order to encourage the patients' interest and participation, "cheerful and pleasant manners" from the asylum staff were instrumental. ${ }^{121}$ By congenially conducting themselves among the patients, the staff also provided an example of socially acceptable behaviour:

The attendants are expected to be examples to the patients of personal neatness, respectful demeanour towards superiors, punctuality, habits of industry, mutual obligingness, and proper moral conduct; it is especially true in dealing with the insane that example is better than precept. ${ }^{122}$

In this way, the staff guided the patients towards improving their actions by personifying conduct that was above reproach. ${ }^{123}$ Thus, Greenlees fervently believed that a good example set by the asylum staff would have a formidably beneficial therapeutic effect on the patients by showing them how to respond and interact in appropriate ways:

I am anxious that instead of being merely the keeper of your patients, the gaoler who prides himself in his possession of the keys of liberty, you may become their friend, companion and nurse, and that your good example may always be before them as an encouragement to good behaviour. ${ }^{124}$

Even when confronted by troublesome and abusive patients, the members of staff were required to exercise patience and kindness, to follow the dictum of " $A$ soft answer turneth away wrath". ${ }^{25}$ If all these options failed, the staff was offered one other retort "silence is often the best answer to such abuse". ${ }^{126}$ By refraining from anger, the staff was able to maintain the appearance of orderly conduct and thereby continue to exemplify model behaviour.

Although it is certain that the behaviour and conduct of asylum staff never attained the ideal that Greenlees had hoped for, it nevertheless remains important to consider how such ideals, when inscribed into the regulations and rules of the asylum, become a tool for instilling behaviour norms. In other words, at the very least, the training that the staff received and the rules of the asylum can be read as an institutional practice that aimed to train, inscribe and correct the behaviour of the staff. Failure to conform to Greenlees's standards was punished in various ways and in some cases the errant staff member was even dismissed from the employ of the asylum. ${ }^{127}$ Various staff offences and their penalties were outlined in

120. WCARS: CO 7170, Regulations for the management of asylums.

121. Greenlees, The Nursing and Management of the isane, $\mathrm{p} 7$.

122. WCARS: CO 7170, Regulations for the management of asylums.

123. Greenlees, The Nursing and Management of the Insane, p 12.

124. Greenlees, The Nursing and Management of the Insane, pp 14-15.

125. WCARS: CO 7170, Regulations for the management of asylums.

126. WCARS: CO 7170, Regulations for the management of asylums.

127. The annual reports provide a chronicle of the various staff offences. These include attendants being dismissed for drunkenness and absenting themselves without leave. A notable case occurred in 1893 when a staff member, who was found being cruel and unkind to a patient, was dismissed from the asylum and prosecuted by Greenlees. See AM: A (vol. 5), Reports on asylums for 1892, 1893. 
the 1897 Lunacy Act. To illustrate one penalty, any staff member who was convicted of ill-treatment or the wilful neglect of patients was "liable to a penalty not exceeding fifty pounds, or to imprisonment, with or without hard labour, for any period not exceeding six months". ${ }^{128}$

The work of the nurses and attendants has thus far been figured as central to the offerings and operations of moral therapy at the asylum. ${ }^{129}$ However, the duties of the staff also closely resembled those of a domestic servant. ${ }^{130}$ They were responsible for the general cleanliness of the wards and the day-to-day assistance and support of the patients. The configuration of the nurses and attendants as closely aligned to servants can be regarded as a strategic operation of surveillance in a Foucauldian reading. To elucidate further, the staff carrying out of the patients' orders offered an opportunity for surveillance under the pretence of service:

The servants apparently obey the patient's orders and give them material assistance, but they do so in such a way that, on the one hand, the patients' behaviour can be observed from behind, underhand, at the level of the orders they may give, instead of being observed from above, as by the supervisors and the doctor. In a way, the servants will thus set up the patients, and observe them at the level of their daily life and from the side of their exercise of will and their desires; and they will report anything worth noting to the supervisor, who will report it to the doctor. $^{131}$

Thus, while endeavouring to assist the patients, the staff was, in actual fact, still exercising supervision over them. For Greenlees, the appeal of such an operation of observation was that the patients were not fully aware that they were being "closely watched". ${ }^{132}$ The exercise of supervision at the asylum required not only continual attention being given to the patients but also without the patient ever getting "the idea of constant watchfulness into his head" ${ }^{133}$ One reason for this was that the patient might "increase his efforts at eluding our vigilance"134 if they became aware of the proliferation of the surveillance avenues at the asylum. Accordingly, while under the auspices of attending to the patients' needs and wants, the staff were urged to be judicious and perspicacious in conducting their observations. ${ }^{135}$ The results of their observations had to be reported to the medical officer. $^{136}$ In this way, the general regulations for the asylum staff constituted the nurses and attendants as a vital backbone for the operations of patient

128. Cory Library for Humanities Research, Rhodes University, Grahamstown: PR 10360 Fort England patient register Book 3

129. S. York, "Alienists, Attendants and the Containment of Suicide in Public Lunatic Asylums, 1845-1890", Social History of Medicine, 25, 2, 2012, pp 324-342. See also: R. Russell, "The Lunacy Profession and its Staff in the Second Half of the Nineteenth Century, with Special Reference to the West Riding Lunatic Asylum", in W.F. Bynum, R. Porter and M. Shepherd (eds), The Anatomy of Madness: Essays in the History of Psychiatry. Volume 3: The Asylum and its Psychiatry (Routledge, London, 1988),

130. Russell, "The Lunacy Profession and its Staff in the Second Half of the Nineteenth Century", p 308.

131. Foucault, Psychiatric Power, p 5.

132. Greenlees, The Nursing and Management of the Insane, $\mathrm{p} 18$.

133. WCARS: CO 1522, Special instructions to the nursing staff having charge of suicidal patients.

134. WCARS: CO 1522, Special instructions to the nursing staff having charge of suicidal patients.

135. Greenlees, The Nursing and Management of the Insane, $\mathrm{p} 18$.

136. Greenlees, The Nursing and Management of the insane, $\mathrm{p} 8$. 
surveillance while establishing a hierarchical line of reporting that ensured that all information was relayed to Greenlees.

The surveillance channels of the patients and the hierarchical relay networks to the asylum management provided an arrangement in which any patient's deviation from the norms of conduct or general defiance could be recorded and corrected. Yet, it is also paramount to acknowledge that such an arrangement recorded not just the patients' disobedience to institutional practices but also the mental state of the patient. The precise workings of this arrangement can be illustrated in the following two quotes:

The attendants are expected to observe the changes which take place in the mental condition, health, or habits of the patients, and to report any new feature, especially any threatening language, any depression of spirits, any suicidal tendency. ${ }^{137}$

Any change in the manner, appearance or expression of such patients, observed by the Attendant, must be reported at once to the Head Attendant; and any remarks of a suspicious character made by a suicidal patient should be noted and reported without loss of time. ${ }^{138}$

Here the mental health of the patients was monitored along with their conduct and obedience to institutional rules. Hence the surveillance arrangement at the asylum departs from being a tool purely assigned for the purpose of discipline and instead exemplifies a much more nuanced usage. Potentially, such an arrangement presents an apt approach to identifying the early onset of relapses into illness or suicidal signs as well as establishing early interventions for the care and treatment of patients. In this light, the gaze of the asylum surveyed the patients for states of fatigue, anxiety, stress and despair, in order to deliver an efficient and rapid intervention for the afflicted patient. This may be a legitimate trajectory when one considers Greenlees's drive towards establishing the asylum for the treatment of acute and recent cases of insanity. As such it was necessary for Greenlees to deliver humane standards of care, to safeguard the patients from injury and to promote their recovery and restoration. Additionally, to maintain the public's confidence in the establishment, Greenlees sought to avoid any incidents or accidents in which the image of the asylum could be brought into disrepute. ${ }^{139}$ For example, patient suicides would have harmed and contradicted the destigmatised image that Greenlees's sought for the asylum. ${ }^{140}$

\section{Economic imperatives and humanitarian care for black patients}

The segregation of white and black patients can be regarded as one of Greenlees's major concerns. Greenlees's motives for the separation of the races

137. WCARS: CO 7170, Regulations for the management of asylums.

138. WCARS: CO 1522, Special instructions to the nursing staff having charge of suicidal patients.

139. Greenlees, The Nursing and Management of the Insane, p 16.

140. Sarah York argues that asylum staff prioritised the task of suicide prevention as any failures signalled poor management and were subsequently investigated by inspection committees. Overall, York indicates that the asylum staff "shared a vested interest in preventing suicides to avoid both disciplinary action, which could result in dismissal or a fine, and maintain the reputation of the institution. They were also motivated by an altruistic desire to prevent suicide for its own sake, to prevent harm and suffering to patients". See York, "Alienists, Attendants and the Containment of suicide", p 324. 
were presumably motivated by the prejudices of the white settler community who believed that they "should not be allowed to associate with the native insane". ${ }^{141}$ Greenlees's interest in serving the prejudiced values of the white community can be understood in terms of attracting and gaining private patients as one way to please the cost-conscious authorities. ${ }^{142}$ The high cost of maintaining patients in "the complicated and expensive machinery of an asylum"143 was acknowledged by Greenlees as an enormous burden on the colony. In order to mitigate the costs of running the asylum, he paid much attention to private patients "as a source of revenue". ${ }^{144}$ Thus, for Greenlees "a legitimate means for assisting in reducing the total cost of the upkeep of the Asylum"145 was the intake of private patients. A second means was using the black patients as an unpaid labour force to assist with the routine maintenance and domestic tasks. ${ }^{146}$

In this way, the preferential treatment of white patients and the labour of black patients existed as an expression of increasing the profits of the asylum while reducing its expenditure. Greenlees's preoccupation with racial segregation therefore engages with grappling with asylum revenue and expenses as well as the demands of the white clientele.

Yet there might also be a possibility to accord a humanitarian interest in Greenlees's economic practices at the asylum. For the colonial government, the gaol provided an inexpensive alternative to accommodation in an asylum. Greenlees was particularly scornful of the government detaining black patients in gaols. ${ }^{147}$ To persuade the government to instruct the magistrates and officials to consign the insane to an asylum required demonstrating that it would not be a tremendous expense to the state. ${ }^{148}$ In this way, asylum labour performed by the black patients not only minimised the overhead costs of the asylum but also ensured their eligibility to the asylum. Although black patients in asylums received

141. AM: A (vol. 5), Reports on asylums for 1893. For Deacon, to understand the process of racial segregation in the medical institutions of the Cape it is necessary to investigate a multitude of factors including the professional concerns of colonial doctors and the internal pressure from the patients who wished to uphold their social status. See H. Deacon, "Racial Segregation and Medical Discourse in Nineteenth-century Cape Town", Journal of Southern African Studies, 22, 2, 1996, pp 287-308. See also Swartz, "The Black Insane in the Cape".

142. See also Deacon, van Heyningen, Swartz and Swanson, "Mineral wealth and medical opportunity". For a discussion of the economics of colonial medicine in the Cape Colony before 1910, see A. Digby, "'A Medical EI Dorado'? Colonial Medical Incomes and Practice at the Cape", Social History of Medicine, 7, 3, 1995, pp 463-479.

143. AM: A (vol. 6), Reports on asylums for 1894.

144. WCARS: CCP $1 / 2 / 1 / 97$, Reports on asylums for 1895 . Specifically the profits obtained from the private patients were placed to the credit of the asylum and thus led to a drop in the total costs of all patients. For example, in 1898 while the cost per patient was $£ 60$. 3s. $11 / 2 d$ per annum, after deducting the income received from various sources (including the sales of goods, income from private patients etc.) the actual cost was reduced to $£ 30$. $1 \mathrm{~s} .03 / 4 \mathrm{~d}$. per annum. Of the various income sources, the amount contributed by paying patients reduced the total costs of all the patients in the asylum by $£ 1616 \mathrm{~s} .43 / 4 \mathrm{~d}$. per patient. See WCARS: CCP 1/2/1/108, Reports on asylums for 1898 .

145. AM: A (vol. 6), Reports on asylums for 1905.

146. Swartz, "The Black Insane"; Louw and Swartz, "An English Asylum in Africa". The performance of labour by patients to defray the costs of asylum residence was a common feature in many asylums. See I. Rosemary, "An Experimental Course of Lectures on Moral Treatment for Mentally III People", Journal of Advanced Nursing, 17, 1992, pp 390-395.

147. AM: A (vol. 6), Reports on asylums for 1902, 1904.

148. AM: A (vol. 6), Reports on asylums for 1904. 
differential treatment from the whites, they most certainly received better care and provisions than those who were confined in a prison. Even although the asylum for black patients was no doubt similar to a workhouse it was not carceral in the sense of imprisoning patients to lifelong institutionalisation. Instead, the asylum for black patients was also shaped around discourses of cure, care and restoration. ${ }^{149}$ The asylum thus may be posed as a welcome alternative to admittance to a gaol.

The identification and exploration of narratives of care for black patients in the asylum follows Sally Swartz's call for a more nuanced description of the asylum, one that is positioned between the asylum as an institution oppressing and neglecting black patients; and one that strove for humanitarian care for all races. ${ }^{150}$ Swartz's call does not seek to dismiss the importance of studies that underscore how the colonial context had a direct influence on putting in place practices that had racist effects. However, she does point out that they do lead to a degree of over-simplification in the interpretation and understanding of the asylum. The most apparent expression thereof is an engagement "with psychiatry as a particularly cruel form of 'cultural imperialism', with no benevolent intent or effect". ${ }^{151}$ Thus, Swartz advocates an approach to colonial asylum historiography that accounts for both sides - the suppression and mistreatment as well as the humanitarian care for black patients. ${ }^{152}$

The discussion thus far has underscored how the asylum mirrored the outside colonial relations in terms of black patients being tasked with labour and domestic work. Moreover they were segregated from the white patients and offered differential access to resources. However, there remains a possibility to propose that in the asylum, the black patients received a degree of kind and respectful treatment that they would not have otherwise received in the external environment. The nurses and attendants were directed to treat all patients "with uniform kindness and impartiality". ${ }^{153}$ Moreover, they were expected to take a caring and compassionate interest in every patient. ${ }^{154}$ Such guidelines suggest that the asylum staff was expected to treat black patients with the same kindness as the white patients. Greenlees specifically emphasised that the staff through their considerate conduct and contact with black patients, would be able to guide and lead them to right ways of thought and action. ${ }^{155}$ Therefore, the example set by the staff was believed to be essential in the treatment of black patients. In this framework, any faltering of the staff from the set standard "either by our own

149. G.C. Beuschel, "Shutting Africans away: Lunacy, Race and Social Order in Colonial Kenya, 1910-1963", PhD thesis, University of London, 2001, p 176; A. McClintock, Double Crossings: Madness, Sexuality and Imperialism (Ronsdale Press, Vancouver, 2001), p 28; T.L. Savitt, Medicine and Slavery: The Diseases and Healthcare of Blacks in Antebellum Virginia (University of Illinois Press, Chicago, 2002 [1978]), p 248.

150. S. Swartz, "Colonial Lunatic Asylum Archives: Challenges to Historiography", Kronos, 34, 1, 2008, p 302.

151. Swartz, "Colonial Lunatic Asylum Archives", p 298. Swartz's approach is shared by a number of recent studies, see Engstrom, "History of Psychiatry and its Institutions"; Parle, States of Mind; Y. Pringle, "Psychiatry's 'Golden Age': Making Sense of Mental Health Care in Uganda, 1894-1972", PhD thesis, University of Oxford, 2013, p 10.

152. Swartz, "Colonial Lunatic Asylum Archives", p 296. In order to offer an example of such a nuanced reading of the asylum, Swartz considers the influential figure of Dodds in his role as inspector of asylums.

153. WCARS: CO 7170, Regulations for the management of asylums.

154. WCARS: CO 7170, Regulations for the management of asylums.

155. Greenlees, The Nursing and Management of the Insane, p 14. 
conduct, or by our treatment to them" would hinder the recovery of the black patients. $^{156}$

The extent to which the staff treated the black patients with kindness and to a degree equivalent to that of white patients may prove impossible to ascertain. Yet, it may also be plausible to argue that asylum staff did not totally neglect the black subjects and that they did derive some benefits from institutional care. This move does not serve to discount the segregation and racism perpetrated at the asylum but seeks to propose that that the asylum regimen perhaps ensured that the black patients did receive an adequate degree of attention to safeguard them from injuries, harm and general neglect.

In sum, the polemical edge of the preceding discussion is that the asylum was not a prison for black patients but rather a hospital for the treatment and recovery of insanity. While the reasons for the authorities admitting black patients to the asylum may have included custodial aspects, the asylum primarily operated with the goal of cure and care in mind, which in turn, meant that the staff was "expected to do its utmost to restore the individual to a productive mental state and prevent the accumulation of long term incurable patients". ${ }^{157}$ Although the recovery rates for the black patients were never high, ${ }^{158}$ each patient discharge has the potential to question the dominant narrative of the asylum as a colonial site solely for the detention and custody of black subjects.

The asylum's casebooks may provide suitable source material to illuminate such insights. For example, on 12 October 1892, a nineteen year old black male was admitted to the asylum by medical authorities for being "off his head", and rather than working he was "doing nothing but wandering aimlessly about". ${ }^{159}$ In less than a month, Greenlees discharged the patient from the asylum as recovered. Greenlees's rationale for the discharge of the patient is meticulously detailed in the following casebook entry:

\footnotetext{
I have held long conversations with him on frequent occasions, and while I was of opinion that he was insane on his admission (see my certificate Oct, $19^{\text {th }}$ ) I now certify that, while he is not of the brightest intellect, he is no longer insane or requiring Asylum treatment. He is quiet, has become industrious in his habits, does not express any delusions even after much cross-questioning. When I asked him if people went to church to sleep, he said, men who went to church when they were tired with work, generally slept after the sermon. I then asked him what he would do with half-a-crown if I gave [it to] him, and he said, he would buy something good to eat, as he required nothing else e.g. clothes. He does not know the name of this place, but says his fellow patients seem all mad. I am further of opinion that [the patient] is an illiterate native, and many of the delusions [...] expressed by him to the medical man who examined him, are simply the result of his ignorance, and that he is no longer insane.
}

156. Greenlees, The Nursing and Management of the Insane, p 14.

157. Beuschel, "Shutting Africans away", p 176.

158. Of the total cases admitted from the opening of the asylum to 31 December 1906, the discharge rate for white patients was $36 \%$ and for black patients it was $28 \%$. See AM: A (vol. 7), Reports on asylums for 1906. See also Greenlees, "Statistics of Insanity in Grahamstown Asylum"; Swartz, "The Black Insane".

159. WCARS: H.G.M. 3, Grahamstown Mental Hospital casebooks. 
While the patient may have come to the attention of the authorities for being an obstinate and unproductive labourer, ${ }^{160}$ the discourses of cure and recovery at the asylum were not simply signalled by his ability to work. ${ }^{161}$ Rather, Greenlees's rationale for discharge was the recognition that the delusions expressed by the patient were not evidence of insanity but a prominent symptom of illiteracy and a lack of education. Thus the casebooks may hold the potential to offer a more nuanced description of the colonial asylum, one that is positioned between the asylum as an institution oppressing and neglecting black patients; and one that strove for the care and treatment of black patients. ${ }^{162}$

\section{Conclusion}

In outlining the character of a medical superintendent, Mercier enumerates that "he must ... know exactly what he wants and see clearly how to get it" ${ }^{163}$ Such a point underscores that the main professional concerns of a superintendent consisted of far more than just administrative and organisational tasks. Instead it also included an individual's vision, goals and beliefs. Along these lines, the study aimed to offer an exploration of the goals and priorities of Greenlees's tenure at the Grahamstown Lunatic Asylum.

From the close examination of the annual reports several key themes are argued to have constituted Greenlees's leadership and priorities at the asylum. A central concern was the construction of a de-stigmatised image of the asylum. One means of doing so was by opening the asylum to visits from the public as well as sending patients out on excursions. Accordingly, Greenlees sought to achieve a porous atmosphere at the asylum in which connections and relations with the outside community were encouraged. Yet, alongside the porous atmosphere, Greenlees equally pursued a form of entry-control - in the form of visiting regulations - to prevent the indiscriminate access to views of the asylum and the patients. Such an argument opens up the possibility for proposing that visiting regulations should be straddled between a desire to make sure that the view of the asylum is mediated, while also guaranteeing that patients are protected from dubious and distrustful visitors.

An essential component in enforcing the visiting regulations and in the implementation of moral therapy was the staff of the asylum. The study outlined in considerable depth how Greenlees conceptualised the role of the nurses and attendants as central to the therapeutic aims of the establishment as well as to the surveillance of the patients' conduct and wellbeing. A key claim forwarded in the study is that the surveillance arrangement over the patients was equally matched by Greenlees's supervision of the staff; a process that aimed to ensure that they were exemplary models of normative conduct, behaviour and respectability.

A conspicuous priority for Greenlees was mitigating the high costs of running the asylum. One means of reducing the total costs was by the revenues received from the private patients. In order to gain their custom, Greenlees

160. Swartz, "Colonial Lunatic Asylum Archives", p 288.

161. R. du Plessis, "Photographs from the Grahamstown Lunatic Asylum, 1890-1907", Social Dynamics, 40, 1, 2014, pp 12-42.

162. Swartz, "Colonial Lunatic Asylum Archives", pp 296; 302.

163. Mercier, Lunatic Asylums, p 197. 
prioritised the class interests and social prejudices of the white patients that resulted in him adopting an extensive programme of segregation at the asylum. While segregation and racism remain the chief markers of institutionalisation for black patients, the study cautioned against asylums being regarded as a direct equivalent of prisons.

Although the period after Greenlees's tenure at the asylum is outside the scope of this study, it is worth noting that:

\begin{abstract}
Many of the best-known medical superintendents in the [South African] mental service have ... won their spurs at Grahamstown, because it has remained a small hospital, and was often a superintendent's first appointment to that post from the lower ranks of the service. ${ }^{164}$
\end{abstract}

Future investigations may pursue this quote by exploring the goals and priorities of the superintendents who were subsequent to Greenlees. It is certain that the investigation of the tenure of each of the superintendents will significantly illuminate the varieties of asylum culture over the course of the institute's history.

\begin{abstract}
By exploring the significant role played by the medical superintendents of lunatic asylums, there is a possibility of enriching our understanding and appreciation of the varieties of asylum culture. Said differently, by investigating the tenure of a superintendent, it is possible to highlight how the individual constructed an asylum to embody a set of goals and principles. Along these lines, the study aims to explore and investigate the Grahamstown Lunatic Asylum, under the medical superintendence of Dr Thomas Duncan Greenlees from 1890 to 1907. In order to explore Greenlees's priorities and primary topics, the asylum's annual reports provide a valuable resource. From the close examination of the annual reports several key topics emerge. The examination of the topics is informed by recent scholarship on moral therapy and Michel Foucault's analysis of power.
\end{abstract}

Key words: Thomas Duncan Greenlees; lunatic asylums; moral therapy; Michel Foucault; Grahamstown Lunatic Asylum.

\title{
Opsomming
}

Die bestudering van die beduidende rol wat mediese superintendente speel in sielsiekegestige kan ons begrip van en waardering vir die verskillende vorms van inrigtingkultuur verryk. Deur die ampstermyn van 'n superintendent te ondersoek, kan vasgestel word hoe dié persoon 'n inrigting opbou om 'n stel oogmerke en beginsels te beliggaam. Op hierdie grondslag beoog die studie ' $n$ verkenning van en ondersoek na die Grahamstown Lunatic Asylum onder dr Thomas Duncan Greenlees as mediese superintendent van 1890 tot 1907. Die inrigting se jaarverslae bied 'n waardevolle bron vir die verkenning van Greenlees se prioriteite en primêre onderwerpe. By nadere ondersoek van die jaarverslae kom verskeie belangrike onderwerpe na vore. Die bestudering van hierdie onderwerpe

164. M. Minde, "History of Mental Health Services in South Africa. Part 3. The Cape Province", South African Medical Journal, 48, 1974, p 2231. 
geskied aan die hand van onlangse navorsing oor morele terapie en Michel Foucault se ontleding van mag.

Sleutelwoorde: Thomas Duncan Greenlees; sielsiekegestige; morele terapie; Michel Foucault; Grahamstown Lunatic Asylum. 